\title{
Specialization and Variety in Repetitive Tasks: Evidence from a Japanese Bank
}

Bradly R. Staats

Francesca Gino

Follow this and additional works at: https://repository.upenn.edu/fnce_papers

Part of the Finance and Financial Management Commons

\section{Recommended Citation}

Staats, B. R., \& Gino, F. (2012). Specialization and Variety in Repetitive Tasks: Evidence from a Japanese Bank. Management Science, 58 (6), 1141-1159. http://dx.doi.org/10.1287/mnsc.1110.1482 


\title{
Specialization and Variety in Repetitive Tasks: Evidence from a Japanese Bank
}

\begin{abstract}
Sustaining operational productivity in the completion of repetitive tasks is critical to many organizations' success. Yet research points to two different work-design-related strategies for accomplishing this goal: specialization to capture the benefits of repetition and variety (i.e., working on different tasks) to keep workers motivated and provide them opportunities to learn. In this paper, we investigate how these two strategies may bring different productivity benefits over time. For our empirical analyses, we use two and a half years of transaction data from a Japanese bank's home loan application-processing line. We find that over the course of a single day, specialization, as compared to variety, is related to improved worker productivity. However, when we examine workers' experience across a number of days, we find that variety helps improve worker productivity. Additionally, we show that part of this benefit results from workers' cumulative experience with changeovers. Our results highlight the need for organizations to transform specialization and variety into mutually reinforcing strategies rather than treating them as mutually exclusive. Overall, our paper identifies new ways to improve operational performance through the effective allocation of work.
\end{abstract}

\section{Keywords}

learning, motivation, productivity, specialization, variety, work fragmentation

Disciplines

Finance and Financial Management 
H A R VARD

\title{
Specialization and Variety in Repetitive Tasks: Evidence from a Japanese Bank
}

\author{
Bradley R. Staats
}

Francesca Gino

\section{Working Paper}

11-015 


\title{
Specialization and Variety in Repetitive Tasks: Evidence from a Japanese Bank
}

\author{
Bradley R. Staats \\ University of North Carolina at Chapel Hill \\ Campus Box 3490, McColl Building \\ Chapel Hill, NC 27599-3490 \\ Tel: 919.962 .7343 \\ Fax: 919.962.6949 \\ bstaats@unc.edu \\ Francesca Gino \\ Harvard Business School \\ Harvard University, Baker Library \\ Boston, MA 02163 \\ Tel: 617.495 .0875 \\ Fax: 617.496.4191 \\ fgino@hbs.edu
}

April 26, 2011

\section{Acknowledgments}

We are grateful to Masamoto Yashiro, Jay Dvivedi, Michiyuki Okano, Pieter Franken, Yuki Kimura, Aiko Suga, and numerous other individuals at Shinsei Bank for their investments of time and attention to this project, without which the work would not have been possible. We thank Christian Terwiesch, the Associate Editor, and the reviewers for substantive comments that significantly shaped this manuscript. David Brunner, Jonathan Clark, Adam Grant, Dave Hofmann, Rob Huckman, Diwas KC, Saravanan Kesavan, Ann Marucheck, Lamar Pierce, Gary Pisano, Bill Simpson, Jay Swaminathan, Harvey Wagner, and participants at the Conference on Behavioral Research in Operations Management provided helpful comments on earlier drafts of this paper. We also gratefully acknowledge support from the University of North Carolina's Center for International Business Education and Research. All errors are our own. 


\section{Abstract}

Sustaining operational productivity in the completion of repetitive tasks is critical to many organizations' success. Yet research points to two different work-design related strategies for accomplishing this goal: specialization to capture the benefits of repetition or variety to keep workers motivated and allow them to learn. In this paper, we investigate how these two strategies may bring different benefits within the same day and across days. Additionally, we examine the impact of these strategies on both worker productivity and workers' likelihood of staying at a firm. For our empirical analyses, we use two and a half years of transaction data from a Japanese bank's home loan application processing line. We find that over the course of a single day, specialization, as compared to variety, is related to improved worker productivity. However, when we examine workers' experience across days we find that variety, or working on different tasks, helps improve worker productivity. We also find that workers with higher variety are more likely to stay at the firm. Our results identify new ways to improve operational performance through the effective allocation of work.

Key Words: Job Design, Learning, Productivity, Specialization, Turnover, Variety, Work Fragmentation

\section{Introduction}

\section{A perennial problem in industry has been that of sustaining human productivity over extended periods of time. - Scott (1966: 4)}

From Adam Smith's (1776) pin factory and Frederick Taylor's (1911) brickyards to present-day factories in China, call centers in India, and fast food restaurants and banks in the United States (Upton and Margolis 1992; Huckman and MacCormack 2009), sustaining operational productivity in the completion of repetitive tasks is key to many organizations' success. One tool managers have to address this issue is task allocation, however the appropriate allocation approach to pursue is unclear. On one side, scholars argue for the productivity benefits of specialization. As noted by Adam Smith:

The improvement of the dexterity of the workman necessarily increases the quantity of the work he can perform; and the division of labour, by reducing every man's business to some one simple operation, and by making this operation the sole employment of his life, necessarily increases very much the dexterity of the workman (Section I.1.6, Smith 1776; for related arguments see Newell and Rosenbloom 1981; Boh, Slaughter and Espinosa 2007).

On the other side of the debate, scholars suggest that variety, or executing different tasks, improves performance since workers experience increased engagement with the job (Herzberg 1968; Hackman and Oldham 1976) and potentially gain knowledge that can be applied from one task to another (Schilling et al. 2003; Wiersma 2007; Narayanan, Balasubramanian and Swaminathan 2009).

In this paper, we seek to understand how work can be structured effectively across tasks and over time in order to improve operational performance. We posit that, in order to disentangle the effects of specialization and variety, it is necessary to consider the different benefits that each approach provides over time and with respect to different measures of operational performance. In other words, it is possible to evaluate the operational implications of a specialized or varied task assignment strategy over the course 
of a day or across many days, and the mechanisms through which each strategy affects performance suggest differential benefits.

When a worker completes many tasks during a day, specialization helps the worker quickly complete the focal task (Newell and Rosenbloom 1981; Argote 1999) and limits costly changeovers (Cellier and Eyrolle 1992; Schultz, McClain and Thomas 2003). Additionally, over the course of a day, variety may be sufficiently distracting that mixing the two strategies negatively impacts workers' current productivity. However, this tradeoff between specialization and variety may involve different costs and benefits for productivity when considering multiple work days. Although limiting variety during a day may lead to improved performance the opposite may be true over many days. By completing different, but related task types a worker may identify new best practices and then transfer those practices from one task to another (Schmidt 1975; Ichniowski and Shaw 1999; Tucker, Nembhard and Edmondson 2007). Additionally, the motivational benefits of variety (Hackman and Oldham 1976; Fried and Ferris 1987) are more likely salient when a worker has completed a task a number of times (Ortega 2001). Prior work that examines the individual-level productivity effects of specialization and variety across many days has examined only the possible direct effects of variety (Boh et al. 2007; Narayanan et al. 2009), and has not considered any complementarities that variety may offer over time (Lindbeck and Snower 2000). Here we are interested in whether the returns to prior day specialization are increasing in the prior day amount of varied experience.

Thus, the first three research questions we address in this paper are: (1) Does specialized experience or varied experience have a greater effect on productivity within a single day? (2) How do the combined effects of specialized experience and varied experience, within the same day, affect worker productivity? and (3) How do the combined effects of specialized experience and varied experience, across many days, affect worker productivity?

These three questions focus on a fundamental variable of interest for organizations' operational success: a worker's productivity. Yet, there is a second important variable that, although it has received less attention in the operations management literature, significantly influences operational success: employee turnover. Indeed, maintaining productivity for an organization requires not only addressing factors that speed the completion of the present task, but also keeping workers employed at the firm. Voluntary employee turnover is a costly proposition as exiting workers depart with valuable and difficult to transfer production knowledge (Darr, Argote and Epple 1995; Narayanan et al. 2009) and it is necessary to recruit and train new employees, whose initial productivity is typically low (Staw 1980; Ton and Huckman 2008). Task assignment may not only affect task-level productivity, but it may also impact worker turnover as task variety could lead to increased job engagement (Herzberg 1968; Hackman and Oldham 1976), lower levels of boredom (Warr 2007), and increased job satisfaction (Ichniowski and 
Shaw 1999; Griffeth, Hom and Gaertner 2000). Despite this underlying logic, and its important operational implications, as noted by Humphrey, Nahrgang and Morgeson (2007), no empirical work has examined the relationship between task variety and voluntary turnover. Thus, our fourth and final research question asks: How does variety of tasks affect an individual's likelihood to leave a firm?

In this paper, we address these four questions by using two and a half years of transaction data from a Japanese bank's home loan application processing line. In the next section we motivate our hypotheses. We then introduce our data and empirical results before discussing the implications of the findings and offering concluding remarks.

\section{Specialization and Variety}

The concept of specialization has played a central role in the development of the field of operations management. The Industrial Revolution led to large scale operations creating the need to identify ways to simplify these often complex processes (Skinner 1985). Frederick Taylor stepped into this gap, with his principles of Scientific Management, which involved breaking down a task, optimizing the constituent steps and then focusing workers on repeatedly executing the task (Taylor 1911). ${ }^{1}$ Looking at individual workers, specialization is beneficial since when an individual works on the same task over time, she gains knowledge related to the task which may help improve her performance (Newell and Rosenbloom 1981; Argote 1999; Huckman and Pisano 2006). The knowledge gained may cover many different topics including the specific set of steps to follow, the specialized tools being used, or the customer being served (Argote and Miron-Spektor 2010).

While specialization creates conditions that may foster learning, it also avoids costs that may arise from varied experience. ${ }^{2}$ In particular, a large body of work in the operations management literature examined scheduling and inventory decisions using analytical tools to minimize costly set-ups and changeovers (e.g., Bahl, Ritzman and Gupta 1987; Allahverdi, Gupta and Aldowaisan 1999). Further work tackled the problem by considering how to decrease the time for set-ups in order to eliminate waste (e.g., Shingo 1989; Tzur 1996). More recently studies have considered that not only do machines require setups and changeovers, but so too do people (Simons and Russell 2002; Schultz et al. 2003).

\footnotetext{
${ }^{1}$ While Taylor's work concentrated on the benefits of specialization at the individual level, subsequent work in operations management has examined the topic at the operating unit level, referring to the topic as "focus" (Skinner 1974). This work generally supports the value of focus (Hayes and Wheelwright 1984; Lapré and Tsikriktsis 2006; Tsikriktsis 2007; Huckman and Zinner 2008), but does not always do so (MacDuffie, Sethuraman and Fisher 1996; Mukherjee, Mitchell and Talbot 2000). Recent work unpacks focus further, examining the impact of related activities on focus (Clark and Huckman 2010) as well as the different possible types of focus and their affect on performance (KC and Terwiesch 2010).

${ }^{2}$ While this paper is focused at the individual level work in operations management at the level of a plant considers the cost of variety that arise from the added operational complexity and challenges in assigning workers given the variability in task completion time (e.g., MacDuffie et al. 1996; Fisher and Ittner 1999).
} 
While the learning benefits discussed and the costs of variety, as seen through set-ups or changeovers, point towards an overall benefit of specialization, work in organizational behavior has identified costs to specialization. Much of this research traces its roots to fieldwork that documented the cognitive toll on workers who repeatedly execute the same tasks over time (Roethlisberger and Dickson 1934; Roy 1959). While repeated experience offers opportunity for learning, it also introduces the possibility of challenges with motivation and boredom (Fisher 1993). When a task is repetitive, familiar, or dull, workers are more likely to experience only low levels of cognitive arousal and, as a result, disengage from the task (Warr 2007). Alternatively, they engage in behaviors that, while raising their arousal levels, also detract from job effectiveness (Vroom 1964; Scott 1966; Hackman 1969). Thus, with repetition of the same task, not only might workers be less likely to identify new ways to improve performance, but they also may lose motivation, resulting in decreased performance.

For these reasons, organizational behavior research on job design and motivation stresses the need for task variety (Hackman and Oldham 1976; Ichniowski and Shaw 1999; Humphrey et al. 2007). Changing the task may increase workers' mental stimulation or arousal, as well as their task engagement, thus improving performance (Langer 1989). Additionally, task variety can create the opportunity for knowledge transfer between tasks which may result in learning (Schilling et al. 2003; Narayanan et al. 2009). For example, a worker may recognize that a step used in completing Task A may improve her productivity in completing Task B. Additionally, by completing Task A and Task B a worker may recognize a higher order principle that affects both tasks. Given the tension between specialization and variety the question remains - how should repetitive tasks be assigned to workers? We propose that temporal considerations affect the necessary balance between these two strategies.

In this paper, we focus on procedural tasks, or those tasks that "involve series of discrete motor responses (responses with a distinct beginning and end). The responses themselves are easy to execute; it is deciding what responses to make and in what sequence that pose the main problems for the learner" (Schendel and Hagman 1982: 605). Examples of procedural tasks include a number of common operational processes such as manufacturing assembly line operations and data entry tasks, such as the ones we study here. Thus, in completing procedural tasks a worker must exert herself both physically and mentally. Problem-solving by front-line workers completing procedural tasks can yield significant operational improvements (e.g., Spear and Bowen 1999), however workers' problem solving efforts are limited by the scope of their task design. As an extreme example, a worker installing a tire on an automobile is unlikely to change the engine design. While procedural tasks encompass many types of work seen in modern organizations, they do not include what is called by the literature "knowledge work" (e.g., scientists or surgeons, Drucker 1999). 


\subsection{Specialization and Variety during a Day}

We first consider worker task assignment over a day in which a worker completes many tasks and carries no tasks over from one day to the next. Specialization (or at least lower variety) over a day allows a worker to limit changeovers. When a worker switches tasks she needs to relearn or at least reacquaint herself with key relevant processes (Bailey 1989; Nembhard and Osothsilp 2001). This reacquaintment effect is similar to a setup for a machine, and results in decreased productivity. Laboratory studies find that switching tasks worsens performance (Cellier and Eyrolle 1992; Allport, Styles and Hsieh 1994; Schultz et al. 2003).

Specialization over the course of a day also offers potential learning benefits as well. With repetition, a worker not only gains mastery of the individual steps in a task, but also may see how the pieces fit together and recognize opportunities for improvement (Jaikumar and Bohn 1992). For example, in the context of data entry, a worker might recognize that the current task requires more frequent shifting of her field of vision from the form to the computer screen than a prior task (e.g., one field at a time as opposed to two fields at a time due to the complexity of the data).

The benefits of specialization may hold even if the worker has executed a task many days before. For example, not only is there a risk that she may have forgotten prior knowledge (Bailey 1989; Argote, Beckman and Epple 1990), but the same day experience should help her move all relevant knowledge into short-term or working memory for easier access (Baddeley 1992). This could function in a manner similar to a computer's moving programs or data from long-term memory into a more rapidly accessible cache to improve performance. Same day experience potentially offers workers not only mental benefit, but physical benefit, as well: as individuals begin to execute tasks, they gain muscle memory to improve productivity. While executing the same task repeatedly in a given period, a worker may get into a groove, steadily improving performance (Quinn 2005).

Despite these benefits to specialization, organizational behavior work on motivation and job design suggests that task variety is necessary to maintain worker productivity (Fried and Ferris 1987; Humphrey, Nahrgang, and Morgeson 2007). However, while changing tasks may provide some motivational benefit, we posit that this benefit is likely offset by the gains of specialization during a day. Although variety can also lead to learning, we expect that learning is unlikely to manifest itself in a substantial way during a single day. Recognizing opportunities for performance improvement typically requires reflection (Argyris and Schön 1978; Edmondson 2002), a process that is difficult to do during the course of a busy day filled with repetitive tasks. Thus, while variety during a day may still improve 
performance on a focal task, it is unlikely to do so more than a specialized strategy. ${ }^{3}$ Additionally, we expect the interaction of varied and specialized experience to have a negative impact on performance, due to the potential distracting effects of variety. When workers are forced to engage in multiple changeovers they are then using valuable cognitive resources to acclimate to the new task, as opposed to performance improvement. Additionally, while changing tasks within the same day a worker may not recognize that the performance strategy used on one task is sub-optimal on another. Therefore, we offer the following two hypotheses:

HYPOTHESIS 1: $\quad$ Same day, same task experience has a greater effect on worker productivity than does same day, different task experience.

HYPOTHESIS 2: $\quad$ The combined effects of same day, same task experience, and same day, different task experience (i.e., their interaction effect) decrease worker productivity.

\subsection{Specialization and Variety over Many Days}

While we hypothesize that specialization will dominate variety within a day, we posit that variety may prove beneficial over many days. Over time a worker may be able to identify learning opportunities across various types of tasks. For example, a worker may recognize that a strategy used in one task can be used profitably in another area or may realize that parts of strategies used in multiple tasks may be combined to yield a better performance outcome. Also, while the additional setups from task change are still costly over time, the negative effects of specialization likely grow more salient as a worker completes more tasks and grows bored with work. With increasing variety she may remain engaged with the work and thus continue to improve her performance or alternatively, not see her performance degrade.

The question is how this effect will manifest itself in worker productivity. It seems likely that, for lower levels of experience specialization will provide greater benefit than varied experience (Boh et al. 2007). However, the returns from specialization likely decrease at a faster rate than the returns from varied experience given the motivation challenges previously discussed. Our hypothesis focuses on potential complementarities between specialized and varied experience. In particular, not only may varied experience result in direct performance benefits for current productivity (e.g., by bringing a

\footnotetext{
${ }^{3}$ This expectation runs counter to the findings of Schilling et al. (2003) where students in the lab for one day improved their performance most when playing two, related games (i.e., not one game). Over and above the fact that the prior study involved teams of students whereas we study individual workers pursuing their profession, there are at least three differences that lead us to expect different within-day effects. First, students were playing games on the computer. These games were considered fun and involved only problem solving (i.e., no mix of physical and mental exertion). Thus, the task is very different from our procedural task context. Second, students were told to play at their own pace, and so had ample time for reflection, if desired. Finally, students had not played the game before and only played it for one day, while we are examining workers who repeat work day after day.
} 
particular performance strategy over into the new context), but it may offer an ongoing benefit. This idea is captured in the theoretical model of Lindbeck and Snower (2000) who argue for returns from task complementarities, suggesting that a worker's experience with “one task raises his productivity at another task (p. 359)." The complementarity may arise for learning reasons - varied experience may aid in learning how to learn (Ellis 1965) or it may also help to trigger a different learning process where discrepancies cause a worker to change her underlying theories about the process (Piaget 1963), resulting in performance improvement. Alternatively the benefit may be motivational, as varied experience keeps a worker engaged so that she is willing to continue to take part in performance improvement. While Lindbeck and Snower's model captures only one time period, they note that returns from complementarities should "manifest themselves only with the passage of time (p. 360)." Given these reasons we hypothesize:

HYPOTHESIS 3: $\quad$ The combined effects of prior day, same task experience, and prior day, different task experience (i.e., their interaction effect) increase worker productivity.

\subsection{Specialization, Variety, and Voluntary Turnover}

Sustaining operational productivity not only involves maintaining a worker's task productivity, but also it requires keeping the worker employed at the firm. Prior work on employee turnover finds that high turnover may lead to lower organizational performance (Ton and Huckman 2008) and that departing workers may leave with valuable knowledge (Darr et al. 1995; Narayanan et al. 2009). Furthermore, recruiting and training new employees is expensive, and new employees' initial productivity is typically low (Staw 1980; Ton and Huckman 2008). Several studies on employee turnover have considered what factors may lead a worker to voluntarily leave her job (Price 1999; Griffeth et al. 2000). However, as noted by Humphrey, Nahrgang and Morgeson (2007) in their meta-analytic review of the topic, "little research has examined the relationships between task variety and a number of outcomes." One such unexamined outcome is employee turnover.

Why might task variety be related to employee turnover? Task variety may lead to increased job engagement (Herzberg 1968; Hackman and Oldham 1976) and lower levels of boredom (Warr 2007). Task variety is related to job satisfaction as workers tend to enjoy the cognitive stimulation due to the change in tasks (Fried and Ferris 1987). Since job satisfaction predicts an individual's turnover, this then suggests that task variety may lead to an increased likelihood to stay at the firm (Griffeth et al. 2000). Therefore, our final hypothesis is:

HYPOTHESIS 4: $\quad$ Higher task variety decreases the likelihood that an individual leaves the firm. 


\section{Setting, Data, and Empirical Strategy}

\subsection{Setting}

The setting for our analyses is Shinsei Bank, a mid-sized Japanese bank. In 2004, as demand for mortgages boomed, the bank discovered that, due to its small branch network and a bottleneck in finding expert credit analysts, the operation could not fulfill demand. Shinsei turned to information technology to solve the problem (Citation withheld). The company's IT personnel deconstructed the home loan application into its constituent pieces. The company then devised an internal production line in which workers entered the necessary data to construct a virtual credit folder and a credit decision was made.

By mid 2007, the process was structured as outlined in Figure 1, with those parts of the process in black being completed automatically by computers and those parts of the process in white being completed by human operators; these latter parts of the process serve as the focus for our analyses. Below we explain the process sequentially for ease of understanding; however, an application need not proceed strictly in the manner described. Multiple parts of the process between decision points can run in parallel, and in fact they do.

As Figure 1 shows, the process begins when an application is received and scanned. While the scanning does involve some human input (e.g., operator places application into machine), we do not include scanning in our analyses, in part because scanning is the only stage whose completion time is not captured at a sufficiently minute level. One operator might open the envelopes while another operator might place a stack of applications in the scanner. Additionally, scanning takes place in another part of the building, and it is done by different individuals than those who figure in the remaining stages.

*************************************) Insert Figure 1 about here $* * * * * * * * * * * * * * * * * * * * * * * * * * * * * * *$

After scanning, forms go to the custodian stage. During this stage, a worker compares the scanned image to the document and either accepts or rejects the scan. Any image rejected is returned to scanning, where the process begins again. After the custodian stage is completed, documents are tagged: subsections of each scanned document are marked electronically (tagged) for future processing. Next, the application is "captured": workers input data from the application into the computer system. Specifically, each worker sits at a computer equipped with two monitors. On one screen, the worker is presented with an image of the application; on the other, she enters relevant data in the appropriate fields. Separate parts of the application are entered in the Application capture 1 and Application capture 2 stages. During the subsequent preliminary information part of the process, several data fields from the remainder of the application are recorded by workers using the approach just described. Preliminary information 1 enters one set of data, while Preliminary information 2 enters data from different images of the application.

After this work is completed, the inputs are compared to underwriting standards (within the 
computer system). If the application fails to meet standards, an automatic rejection letter is sent. If the application passes, the computer checks to see if the application is complete. If it is missing data, then a request for more information is generated automatically; and when the additional information arrives, the entire application is processed again. If no data is missing, the application proceeds to credit check. In the first stage of credit check, a worker enters the data needed to request an external credit report. In the second stage, a worker types in relevant fields from a scan of the faxed credit report. The computer then compares the application again to underwriting standards, and if it passes, generates a request for more materials from the prospective borrower. The company also has call center operations to handle customers' inbound questions and to make outbound calls encouraging submission of paperwork, but these are outside the scope of the present study and thus are not included in data analyzed here.

Once the additional data is received and scanned, it proceeds through new custodian, document tagging, and two additional application capture stages (all defined as separate stages, given the work is different from the earlier stages with the same names). After the file is checked by computer for completeness and comparisons against underwriting standards, it proceeds to income tax. In the first stage, a worker submits a request to the Japanese tax authority for verification of income tax forms; in the second stage, the authority's response is entered. The file is checked again by computer against underwriting standards before progressing to real estate, whose first stage requests a real estate appraisal from an outside party, followed by the next stage, entering the data. The final stage we analyze is credit approval, which is completed not by a specially trained credit expert, but rather by a line worker. This worker examines the application against a number of prespecified standards. The comparisons show up as green (when acceptably above standard), red (when unacceptably below standard), or yellow (marginal). If the application meets or fails to meet the standard, the worker approves or rejects it, accordingly. If the application is marginal or the worker believes special circumstances exist, she can send it to a manager for further examination. We have no data on this further examination, so it is excluded from our analysis. Table 1 provides a brief description of the stages in the overall process.

*********************************Insert Table 1 about here $* * * * * * * * * * * * * * * * * * * * * * * * * * * * * * *$

To summarize the structure of the Shinsei line, each of the seventeen stages analyzed is distinct. When a worker is assigned a task within a stage (e.g., Application capture 1), she completes all of the work for that stage. There is no physical handoff between workers. When a worker completes her work then the system assigns her a new task - in other words, a worker does not have an individual queue. Lunch and break times are calculated within the system and no work is assigned to a worker during these times. The system provides no information to workers about the state of the queue, rather a worker learns the task to complete when it arrives on her desktop. Line workers are not specialized to a given task (they receive no specialized training) and this includes credit approval. 


\subsection{Data}

Our sample includes all loan applications processed at Shinsei between June 1, 2007, and December 30, 2009: 56,227 loan applications, totaling 601,788 individual stages completed by 140 individual workers. Twenty-nine workers in the dataset appear for less than 200 transactions each. All but five of these workers stay at the firm for only ten days or less and thus are either short-term temporary workers or workers who join and immediately leave the firm (workers have a two week probationary period upon joining the firm). The remaining five individuals are managers who occasionally complete transactions when workers are absent. We drop all of these workers, and their transactions from our analysis leaving us with 598,393 transaction and 111 individual workers. Shinsei's IT systems track detailed information on each loan application as it moves through the process. For each stage, start and finish times are recorded as well as additional information such as an identifier for the employee who completed the work. We use this information to construct the study's variables. We note that Shinsei's employees are paid an hourly rate, with no incentive-based pay for completing tasks faster or with higher quality. Workers do not have a daily quota of tasks to complete and are not given performance targets for their work. Additionally, pay raises are based on firm tenure, not performance. Management reported that no workers were involuntarily separated outside of the two week probationary period.

3.2.1 Dependent Variables. We examine two dependent variables: completion time and turnover.

Completion Time. We measure the first by calculating the number of minutes a worker takes to complete the present stage and taking the natural log of the value to give the completion time. Processing time is a common measure for evaluating operational performance (e.g., Reagans, Argote and Brooks 2005). Shinsei management reported that faster processing time for individual tasks helped in part to enable the company to more quickly process a loan application and that this helped the company compete more effectively as it increased the likelihood of securing a customer. The mean of the unlogged variable is 2.74 minutes and its standard deviation is 3.54 minutes.

Similar to the approaches used by Boh et al. (2007) and Narayanan et al. (2009) we run our completion time analyses on all of the transaction data while controlling for the characteristics of each stage. This approach permits us to examine a worker's complete work history at Shinsei, during the time of our data. We use the analytical framework of the learning curve for our completion time analyses. Scholars have used the learning-curve approach to explore the relationship between experience and performance across various levels of analysis and settings in order to understand performance within organizations (Wright 1936; Argote et al. 1990; Lapré, Mukherjee and Wassenhove 2000). Prior research refers to the learning curve as a progress function and an experience curve, among other terms (Yelle 1979; Dutton and Thomas 1984). For consistency with recent work on the topic, we use the term learning curve in this paper to refer to changes in workers' productivity that are due to task experience. 
However, "experience curve" is conceptually a more precise term in this setting since we are examining how cumulative experience affects performance. The changes that we observe in the data could be the result of learning or the result of increased motivation.

Turnover. Our second dependent measure is employee turnover. Turnover is coded one when a worker leaves the firm and is zero otherwise. Of the 111 workers that appear in the dataset we observe 73 workers depart the firm. Since departure occurs on a daily basis (rather than at the task level), we collapse the dataset for the turnover analyses into day-worker observations. Thus, for the models on turnover all variables are calculated at the end of each prior day.

3.2.2 Independent Variables. Choosing a formalization to operationalize variety is an important design choice. There are at least two basic approaches. The first is to use a volume measure for both stagespecific and all other stage experience. The second is to use a share-based measure (such as a percentage) to examine the effect of differing types of prior experience. We use the former approach for our completion time analysis, both to be consistent with prior literature at the individual level (Boh et al. 2007) and because we are interested in task allocation at a micro-level. In other words, we are concerned with where an additional task should be allocated (i.e., to specialized or varied experience) based on the amount of prior experience that a worker has. We switch to a share-based measure of variety for the turnover hypothesis since departure takes place on a daily basis and we are interested in how the mixture of overall cumulative volume leads to departure. A volume-based measure for turnover would require designating a focal experience type (as in the completion time analyses).

Stage-specific volume. To measure stage-specific experience (i.e., task-specific experience), we construct variables that count the number of times an individual has executed the focal stage previously. We calculate both same day stage-specific volume and prior day stage-specific volume. For the same day stage-specific measure we zero it out at the start of each day and then count the number of times a worker executes that stage on the particular day, prior to the execution of the current task. The prior day stagespecific measure counts the number of times an individual has executed the focal stage prior to the start of the current day. Thus, while same day stage-specific volume changes during a day, prior day stagespecific volume does not.

Other stage volume. We also calculate similar measures for other experience for each worker. First, we calculate same day other stage volume. This measure is zeroed out at the start of each day and captures the number of times a worker has executed all other stages on a given day. Next, we calculate prior day other stage volume. This variable counts the number of times an individual has executed all other stages prior to the start of the current day.

In our models. we include the quadratic variable for both prior day volume measures, but not the same day volume measures. Theoretically, we anticipate that the learning curve for prior day volume 
may turn negative, but we do not expect to see this effect for experience within a day (the exponential model accounts for decreasing returns in both cases). Following the logic of Staw (1980), we expect the curves for prior day volume to exhibit negative returns because while skill is likely monotonically increasing, at a decreasing rate, with cumulative volume, effort (or alternatively motivation or enthusiasm) is likely decreasing in cumulative volume at a potentially increasing rate. Therefore, there is likely a point at which the losses from decreased effort overcome the gains from skill and create negative returns to volume. This point again highlights the need to think of the estimated curves as experience curves. Additionally, we note that if we include the quadratic terms for both same day volume measures then we find that each term is significant, but the negative returns do not occur until the $99^{\text {th }}$ percentile of the distribution. Therefore, we exclude the variables from the analyses, but note that all hypotheses hold with them included.

We do not log any of our experience measures, as we use the exponential form for our learning curve analyses. We use the exponential form for two reasons. First, while the exponential form is derived from theory and supported empirically, the power form (log-log) comes simply from empirical observation (Levy 1965; Lapré et al. 2000). Second, as Lapré and Tsikriktsis (2006) note, if experience is gained prior to the start of data collection, then the power form will be biased. While our data captures the start of the entire IT-enabled work process, some individual stations came online before June 2007; thus, some workers had acquired prior experience.

Total variety. Our final independent variable, used in the turnover analysis, measures the variety of an individual's prior experience. Similar to Narayanan et al. (2009) we start with the Herfindahl index in order to measure variety. This measure is calculated by identifying the percentage of an individual's total, prior experience that is represented by each stage, then squaring that value and summing the components. However, since a larger value for the Herfindahl index is related to increased specialization, we subtract the index value from one. The result, total variety, is also known as the Blau index (Harrison and Klein 2007). The measure is updated to include all experience prior to a focal day. Thus, if an individual has worked on only one stage then her distribution of experience would equal to $1-1=0$. Alternatively if an individual's prior experience was divided equally between four stages then her score would equal $1-\left(\frac{1^{2}}{4}+\frac{1^{2}}{4}+\frac{1^{2}}{4}+\frac{1^{2}}{4}\right)=\frac{3}{4}$. The minimum value for total variety is zero while the maximum is equal to $\frac{n-1}{n}$, where $n$ is the number of stages on which an individual has worked.

3.2.3 Control Variables. Table 2 provides detail on the additional variables included in the analyses to control for a number of factors that may impact performance.

$* * * * * * * * * * * * * * * * * * * * * * * * * * * * * * * *$ Insert Table 2 about here $* * * * * * * * * * * * * * * * * * * * * * * * * * * * * * * *$

As a final point, we note that we have no data regarding the characteristics of individual loans 
(e.g., description of the borrower, amount of loan), and therefore include no controls around these factors. Two reasons lead us to believe our results are robust, however, even without these controls. First, according to Shinsei personnel, differences in borrowers or loan size do not affect loan processing, just the credit decision. Second, and more importantly, loans within a stage are assigned randomly. The IT system presents a task to a worker when she finishes her prior task without regard to loan characteristics.

Tables 3 and 4 provide summary statistics for the variables used in the completion time and turnover models, respectively.

*****************************Insert Tables 3 and 4 about here $* * * * * * * * * * * * * * * * * * * * * * * * * * * *$

\subsection{Empirical Approach}

We run separate regression models for each dependent variable in order to examine the hypothesized relationships. First we estimate a model that captures the effects of specialized and varied experience on task-level performance. The dependent variable is the log of the completion time for task $k$ in stage $i$ completed by individual $j$ :

\section{$\ln (\text { Completion Time })_{i j k}=$}

$\beta_{0}+\beta_{1}$ Same Day Stage-Specific Volume ${ }_{i j k}+\beta_{2}$ Same Day Other Stage Volume $_{i j k}+$

$\beta_{3}$ Same Day Stage-Specific Volume ${ }_{i j k} x$ Same Day Other Stage Volume $e_{i j k}+$

$\beta_{4}$ Prior Day Stage-Specific Volume $e_{i j k}+\beta_{5}$ Prior Day Stage-Specific Volume $e_{i j k}^{2}+$

$\beta_{6}$ Prior Day Other Stage Volume $_{i j k}+\beta_{7}$ Prior Day Other Stage Volume $e_{i j k}^{2}+$

$\beta_{\mathrm{s}}$ Prior Day Stage-Specific Volume ${ }_{i j k} x$ Prior Day Other Stage Volume $\mathrm{i}_{i j k}+\beta_{9} X_{i j k}+\lambda_{\mathrm{t}}+u_{i j k}$

where $X_{i j k}$, is a vector of the individual-task control variables discussed earlier and $\lambda_{t}$ is a year indicator to control for unobserved factors that could affect the average trend in completion time.

In terms of our hypotheses, Hypothesis 1 predicts that over the course of a day, variety will lead to increased completion time as compared to same-stage experience, or that $\beta_{1}<\beta_{2}$. Hypothesis 2 then predicts that the interaction of same day stage-specific and same day other stage volume will be positive, or that $\beta_{3}>0$. Additionally, Hypothesis 3 predicts that the interaction of prior day stage-specific volume and prior day other stage volume will be related to improved productivity, or that $\beta_{8}<0$. We note that given our expectation for different within-day and across-day effects for variety it is important to examine the two within the same model. For example, examining total stage-specific and total other stage experience in a separate model would mask the expected detrimental effect of within-day variety.

Since our data is a complete history of each individual's work volume over three years, we are examining time-series cross-section data (Beck 2001; Lapré and Tsikriktsis 2006). Therefore, we need to select a model that accounts for autocorrelation, contemporaneous correlation, and heteroskedasticity. As detailed by Lapré and Tsikriktsis (2006), we use Prais-Winsten regression with panel-corrected standard 
errors adjusted for heteroskedasticity and panel-wide first-order autocorrelation (Stata command: xtpcse).

Next we consider the relationship between variety and a worker's likelihood to leave the firm. To estimate this effect, we rely on a Cox proportional hazards regression model (Cleves, Gould and Guiterrez 2004). Defining failure as a worker who leaves the firm we estimate the hazard rate of an individual $j$ as: $h\left(t \mid \mathbf{x}_{j}\right)=\mathrm{h}_{0}(t) * \exp \left(\mathbf{x}_{j} \boldsymbol{\beta}_{\mathbf{x}}\right)$

Where, in our case, the regression coefficient of interest is total variety. Additionally, we control for an individual's days working at the firm, monthly utilization, as well as an indicator for the year. We do not include the other control variables from the completion time model as they are all within-day variables (e.g., stage change) and the unit of analysis for this model is day-worker observations.

As we are interested in the effect of variety for a given level of volume we use cumulative volume as the analysis time. The concept is similar to evaluating when a machine fails based on the number of parts it produces (Cleves et al. 2004). We rely on a worker's total, cumulative volume, as opposed to stage-specific volume since we are interested in how all volume over time affects a worker's likelihood to leave the firm. Standard errors in the regression models are clustered by individual worker. We implement the Cox proportional hazards regression model in Stata using the command stcox. Hypothesis 4 predicts that variety will lead to a decreased likelihood to leave the firm, or that the coefficient on variety will be less than zero. In other words, when comparing workers with the same amount of volume at the firm, the worker with higher variety will be less likely to depart the firm.

\subsection{Data Generation Process}

An important question arises about the underlying data generation process for our study. The concern is that variety may be endogenously assigned. As described above, when Shinsei management redesigned the home loan mortgage processing line their goal was to remove the human element from as many parts of it as possible. In describing the thinking behind the redesign, a Shinsei senior manager noted, "When the machines orchestrate the work the people can just be plugged in."

Therefore, at Shinsei, management reported that variety was not considered as a choice variable in the assignment of work. Rather, workers were assigned to a given stage at the start of the day. The system did this automatically although it was likely to keep workers at their last station, if possible (the departure or absence of a worker at another station could lead to a change). Then, during the day, if the system identified a backup at a given station it would "switch" the next available worker to the new task. Depending on the demand dynamics the system could reallocate workers repeatedly over the day. Management reported that workers did not request, and were not given, additional variety in task assignment. Thus, Shinsei managers noted that line managers did not reallocate work or prioritize more

\footnotetext{
${ }^{4}$ Interview conducted with Shinsei senior manager on February 15, 2011.
} 
talented individuals to receive variety, but rather the system was in charge of task allocation.

It is important to note that this process will still yield a positive correlation between variety and cumulative volume. Individuals working for longer time periods are at increasing risk of receiving tasks from a different stage due to a backup in any one area. Thus, we see a positive correlation between prior day stage-specific volume and prior day other volume (correlation coefficient $=0.22, \mathrm{p}<0.01$ ). Additionally, the cumulative volume and variety measures used in the turnover analyses are correlated more highly (correlation coefficient $=0.48, \mathrm{p}<0.01$ ), since this variety measure captures the number of different tasks completed across categories. Workers completing more tasks are at risk to both receive tasks in another area (different from the current one) and to receive tasks across more categories. As long as this assignment occurs as reported, the correlation between the measures does not bias our results.

As an additional check on the assignment of variety, we examined whether, on average, individuals experienced differential task variety within a day. If management was allocating variety in tasks based on the characteristics of workers then we would expect to see persistent variation across our sample. Therefore, we regressed the worker indicator variables and an indicator for each day on workers'

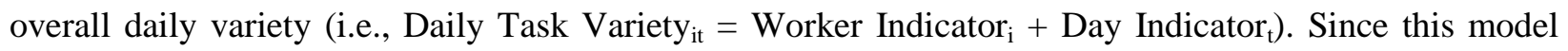
takes place at the daily level (rather than at the task level), we calculated daily variety by constructing a Blau measure (1 - Herfindahl) using just each day's realized volume (i.e., the same approach as described in the total variety variable above, but looking at each day). After running this model using Prais-Winsten regression, we conducted a $\chi^{2}$ test on the individual indicators and the p-value was not significant $\left(p=0.87, \chi^{2}(110)=93.52\right)$. The fact that the indicators as a group were not significant, and only seven of the individual indicators were significant (out of 110, so one would expect approximately six false positives for $\mathrm{p}<0.05)$ increases our confidence that task variety is assigned to worker's randomly.

\section{Results}

Table 5 presents results from the regression of completion time on experience. Focusing first on Column 1, the model excluding interaction terms, we see that both daily experience variables are negative and significant. Each additional unit of same day stage-specific volume decreases completion time by approximately $0.035 \%$, or 5.7 seconds for a transaction of average length, while each additional unit of same day other stage volume improves performance by approximately $0.012 \%$, or 2.0 seconds for a transaction of average length. As Hypothesis 1 predicts, the coefficient on same day stage-specific volume is more negative than same day other stage volume and the difference is significant $\left(\chi^{2}\right.$ test: 184.45, $\mathrm{p}<0.001)$. We also find that both types of prior day stage volume exhibit a U shaped relationship with performance and that, as expected, the linear term for prior day stage-specific volume is smaller than the linear term for prior day other stage volume, while the quadratic term for prior day stage-specific 
volume is greater than the quadratic term for prior day other stage volume. This suggests that while prior day specialized volume has a greater effect on performance than does prior day other volume, for lower levels of volume, the gains from prior day specialized volume decrease more rapidly than do the gains from prior day other volume.

**************************INSERT TABLE 5 ABOUT HERE**********************

Moving to Column 2 we examine the coefficient for the interaction of same day stage-specific volume and same day other stage volume and we find that it is positive, providing support for Hypothesis 2. In other words, increasing an individual's variety of experience over the course of a day decreases the marginal benefit of each subsequent task being executed on the individual's task productivity. Next, we see that the coefficient on the interaction of prior day stage-specific and prior day other stage volume is negative and significant, providing support for Hypothesis 3. To examine the interaction further, we plot the net effect of the interaction (main effects added to the interaction terms for multiple values of experience, see Figure 2) and the plot supports the view that varied experience is related to ongoing performance improvement. In Column 3, we include all four possible interaction terms for the prior day volume measures (i.e., interacting all linear and quadratic terms for the prior day volume measures). Figure 3 plots these values. As the figure shows, varied experience eventually is related to superior performance, as compared to specialization. Note, with the full expansion, a specialized strategy lags both variety strategies at the beginning, then surpasses both varied curves, although by approximately 2,800 and 3,600 units of same day stage-specific volume (both values less than one standard deviation above the mean), strategies including more variety are related to better performance.

**************************** FIGURES 2 \& 3 ABOUT HERE************************

We note that, in addition to our hypotheses, several other coefficients in the model are of interest. First, consistent with KC and Terwiesch (2009) we find that increasing the load on workers during a shift is related to decreased processing times. However these gains do not appear to be sustainable as worker overwork is related to increased processing time. Second, we see that higher levels of monthly utilization are related to decreased processing time. Thus, in including these variables in our models, we not only control for factors that may influence our results, but also we are able to replicate the findings of $\mathrm{KC}$ and Terwiesch (2009) in a non-healthcare setting, showing that service rates are endogenous to the load on a system (Schultz et al. 1998). Additionally, we find that task change (i.e., switching stages) is related to higher average completion times, providing support for the laboratory findings of Schultz et al. (2003). When information workers switch from one task to the next it is necessary to engage in a cognitive setup time and this slows productivity.

Next, in Table 6 we report the coefficient values for the day and year indicators from the models in Table 5 (excluded from Table 5 due to space limitations). We find that, on average, completion times 
are slower on Monday, as compared to any other day of the week and that they are fastest on Saturday. Saturday is a day where volumes are lower and workers are sent home when the day's work is completed so it is possible that workers may be eager to finish their work more quickly, since they leave when the day's work is completed. This suggests that not only do incentives work in this context, although the company does not use monetary incentives to encourage faster completion time, but also that there is slack in the system since workers can complete the tasks faster without negatively impacting quality. ${ }^{5}$

**************************INSERT TABLE 6 ABOUT HERE**********************

Finally, we note that the variable for the year 2009 is positive and significant, indicating that holding all other variables constant completion times in 2009 were slower than in 2007 or 2008.2009 was an exceptional year in the global financial markets due to the liquidity crisis around the world that restricted lending. When asked about this decrease in productivity in 2009, a Shinsei manager speculated that this was due to the lower volume of applications and the general distractions and uncertainty felt by the staff due to the ongoing crisis. While the first point should be largely accounted for in our models as a result of the inclusion of our load and utilization variables, the latter point could lead to the decrease in productivity. For example, prior work suggests that productivity may suffer when there is external uncertainty and a threat of layoffs (although we note that Shinsei did not lay off any workers, Greenhalgh and Rosenblatt 1984). As a robustness check we repeat our analyses excluding 2009 [Column 3]. We find that the results continue to support our hypotheses.

Next, we examine the hazard model in Table 7 to investigate whether variety has a relationship with a worker's likelihood to leave the firm. In Column 1 we see the coefficient for variety is both negative and significant, thus supporting Hypothesis 4. A one standard deviation increase in total variety is related to a $29.9 \%$ decrease in the hazard rate. As expected the coefficient on days working is negative and significant, suggesting the unsurprising result that workers who stay for longer are less likely to leave the firm. We do not find that either system utilization or the year variables are significant predictors of a worker leaving the firm.

*************************INSERT TABLE 7 ABOUT HERE*********************

While our models for completion time use individual indicators to control for time invariant aspects of individual workers, we are not able to include individual indicators in the hazard model since workers only leave the firm once and as such our model compares across workers how differential variety affects an individual worker's choice to leave. There is a concern then that higher skilled workers might receive higher levels of variety, than their less skilled colleagues, and that combined with the positive feedback they get from managers (perhaps informally) this might lead to a worker staying at the firm. If that were the case we would be inappropriately ascribing the worker's decision to stay to the variety in

\footnotetext{
${ }^{5}$ We thank the review team for encouraging this line of thinking.
} 
tasks she received.

Our discussion in Section 3.4 noted that the company reported that variety is not assigned endogenously. However, as an additional check, we examine this concern by constructing a variable, lag month rank. We construct this variable by averaging each worker's completion times over the prior month and then ranking them from one (the best) to $\mathrm{N}$ (the worst), where $\mathrm{N}$ is the number of workers working over that time period. We expect (and find) lag month rank to be negatively correlated with volume, variety, and days at work (see Table 4), since workers who complete more tasks are at risk for more variety (as discussed earlier) and move down the learning curve so their rankings are better. Also, we note that using this definition, new workers, during their first thirty days, do not have a ranking and so are excluded from this analysis.

Column 2 reports the results and we find that while lag month rank is positively related to turnover (in other words, workers with worse rankings are more likely to leave), the coefficient on total variety is still negative and significant, thus supporting Hypothesis 4. We construct rankings using two additional approaches. In the first, we rank workers on each individual stage and then average those rankings for each worker to get an overall ranking. Second, we use the values of the individual indicator variable from the completion time model to rank the workers. The indicator variable notes a worker's intercept and so captures her starting point. Replacing lag month rank with either of these measures does not change our support for Hypothesis 4.

\subsection{Robustness Checks}

To further examine the robustness of our results, we explore several additional factors (results not shown). First, one can consider additional controls for variety. Narayanan et al. (2009) include a Herfindahl-based measure for variety. When included with variables for both specialized and other experience this variable effectively captures how the other experience is distributed. Therefore, we add to the model a Blau measure for prior day variety ( 1 - Herfindahl), that is calculated the same way as the variety measure used in the turnover analysis, except it only includes prior day experience. We also include the interaction of this variable with prior day stage specific volume to capture any additional complementarities between variety and specialized experience. Including these variables does not change the support for our hypotheses. Additionally, while the coefficient on prior day variety is positive $(\beta=0.2645, p<0.001)$ suggesting that having experience distributed across more categories hampers productivity on an absolute basis, the interaction term is negative $(\beta=-4.020 \mathrm{e}-05, \mathrm{p}<0.001)$ suggesting that such variety provides additional marginal value for each unit of specialized volume.

Next, given that the average worker has thousands of observations, there is a concern that the Prais-Winsten panel-corrected standard errors may not adequately account for longer-term 
autocorrelation. Therefore we repeat our analyses with fixed effects regression models with blockbootstrapped standard errors (Stata command xtreg) and continue to find support for our hypotheses. Also, since individuals may learn at different rates we repeat the analyses using a mixed effects model that permits the experience variables and their interaction to vary for each individual (Stata command xtmixed). Using this approach we again find support for the study's hypotheses. Finally, given that we have many workers executing tasks across many stages in our data there is a concern that standard errors might differ across both worker and stage. Therefore, we repeat our analyses using ordinary least squares regression, so that we can cluster our standard errors by worker and stage (Stata command cluster2, Cameron, Gelbach and Miller 2010) and we again support our hypotheses.

We also conduct robustness checks for our hazard analysis. When we include the variable for different stages (discussed above), the coefficient on total variety remains negative and significant. We also include the quadratic for Total Variety and find that it is not significant. Altogether, the additional models increase our confidence that the reported results are robust.

\subsection{Limitations and Venues for Future Research}

While we explored several alternative explanations for our findings and found support for our hypotheses, our investigation is subject to limitations. First, any non-random assignment of variety to individuals could bias our results. While discussions with management make us confident that our results are properly identified, future work could seek to implement a field experiment to further examine our findings. Second, due to factors such as the company's information technology system and the nature of the task, quality is high in this context and shows little variation. While our results are significant both statistically and organizationally, future work could examine the effect of these variables on quality performance and other factors such as workers' creativity and innovation. Third, our analysis examines variety of work. This raises the question of the relatedness of the work we study. In other words, relatedness is in relation to a particular aspect. Boh et al. (2007) and Narayanan et al. (2009) use a software module while Schilling et al. (2003) use a game's appearance to define relatedness. In this study we treat all work as related since all work is related to one product, a home loan mortgage. Tasks in the present context are all related as they involve analyzing and inputting data into a computer. Future work could seek to identify the different dimensions of relatedness and to examine the effects we study in work where tasks differ increasingly one from another.

Fourth, we examine our hypotheses in a procedural task setting. This setting is similar to many operational contexts where workers exert both physical and mental effort. Future work could explore how our findings might differ in a knowledge-based work setting. Fifth, in this study we examine the main effects of task and time characteristics. Future research could examine whether these two factors 
interact to affect performance. For example, it is possible that additional variety could be more (or less) valuable earlier in the day (or week). Additional work, could lead to further insight in using variety to improve worker productivity. Finally, our study examines one organization. This is an undesirable but necessary consequence of both gaining access to such detailed data and learning intricacies of the context. While we believe the theory in our work will hold in other contexts, future work could examine our hypotheses elsewhere.

\section{Discussion and Conclusion}

In most contexts that involve repetitive work, managers have an important decision to make how should they assign tasks to workers? While some scholars argue for specialization (Smith 1776; Boh et al. 2007) others recommend varying the task assignment (Hackman and Oldham 1976; Narayanan et al. 2009). Our findings suggest that the answer to this question is contingent. While a specialized assignment strategy is related to improved productivity during the day, variety is related to improved productivity and an increased likelihood to stay at the firm over time. This suggests that, in contexts with repetitive work, managers should consider keeping workers specialized on a task over a day, while varying task assignments over time.

From a strategic perspective, the question remains: what is the size of the gain that a manager might receive if she played the specialization - variety game strategically? For simplicity sake assume that a worker completes one hundred tasks during a day. Using the coefficients from Table 5, Column 3 we compare the productivity difference for a worker under a specialized (all one task) and a varied strategy (four stages completed 25, 25, 25, 25). Focusing just on the contribution from the same day experience variables (i.e., holding all other variables constant) a worker completing just one task would complete the $100^{\text {th }}$ task approximately $3.8 \%$ faster than average, while a worker completing four different stages would complete the $100^{\text {th }}$ task approximately $2.3 \%$ faster than average - an absolute advantage of one and a half percentage points for the specialized strategy, as compared to the varied strategy.

Looking at the results over time tells a different story. Assuming a worker completes one hundred transactions per day for a total of 10,000 transactions (approximately one standard deviation above the mean) one can consider the overall, experience based differences across a specialized or a varied task strategy (again, four stages completed 25, 25, 25, 25 each day). Holding all of the other variables constant except for the experience and task change variables we find that a worker following a varied strategy completes her work $24.4 \%$ faster than a worker following a specialized strategy. Additionally, for a worker completing tasks in a varied strategy (four stages), the hazard rate for leaving the firm is decreased by $68.0 \%$ as compared to a specialized strategy. Thus, our results suggest that careful task assignment may be able to improve operational performance. 
By examining how work can be structured effectively across tasks and over time, this paper makes several contributions to the existing literature. First, our study builds on recent work on specialization and variety at the individual level (Boh et al. 2007; Narayanan et al. 2009), by examining the topic outside of the software maintenance environment. Resolving a software bug took on average two and a half days in the prior studies, while here we examine a repetitive task that took on average two and a half minutes. Therefore, workers execute more tasks over time and the risk of boredom is likely higher in our study. Also, the data entry that we capture in our study requires less specialized skill than debugging software code. Thus, in our study we are examining highly repetitive, procedural tasks that are both different from software development and representative of many different operational contexts.

Second, we inject the temporal dimension to the debate of specialization versus variety for individual workers looking both within day and across days. By separately evaluating the effect of each strategy over the course of a day and over many days we are able to separate out when and in what way each strategy is related to improved performance. Understanding these differential effects of various types of experience adds value to theorizing on learning and productivity (Argote and Miron-Spektor 2010; Gino et al. 2010).

Third, we consider whether the effect of varied experience on productivity is due to the direct effect of varied experience or from the interaction of varied experience and specialized experience In so doing we are the first to unpack these benefits at the level of the individual (see, Schilling et al. 2003; Clark and Huckman 2010, for analyses at the level of the team and the organization, respectively). Understanding the mechanisms by which variety helps (or hurts) performance creates the ability to theorize more effectively and provide more useful managerial advice.

Fourth, in addition to examining the effect of specialization and variety on worker productivity, we also consider its effect on workers staying at the firm. High turnover may lead to lower organizational performance, but prior empirical research has not examined the effect of variety on turnover (Humphrey et al. 2007). We find evidence that workers who experience higher levels of variety are more likely to stay at the firm. This finding reveals that variety is not only a potential lever to affect long-term productivity, but also it may offer a means of keeping workers at the firm. Furthermore, this result highlights the need for operations management research to examine the effects of operational strategies on multiple outcomes: not only workers' productivity but also their likelihood of remaining at the firm.

Fifth, while Narayanan et al. (2009) conclude that specialization and variety should be balanced, we gain insight into how they should be balanced - over time. Additionally, our complementarities finding highlights that it is not just a matter of balancing the two strategies, but instead, since they are related, it is necessary to find ways to turn the two into mutually reinforcing strategies. 
Finally, our results contribute also to the development of behavioral theory in operations (Boudreau et al. 2003; Bendoly, Donohue and Schultz 2006; Loch and Wu 2007; Gino and Pisano 2008). Our model integrates the operations management and organizational behavior perspectives and thus, with a finer-grained understanding of the relationship between experience and performance, better operating systems can be designed.

Our results also offer implications for managers. Operational circumstances, such as variability in task arrival, will affect a firm's ability to assign tasks on a specialized basis (i.e., it may be necessary to move a worker to meet surprise demand). Nevertheless our findings suggest that managers may be able to use task assignment to improve productivity and perhaps to keep workers at the firm for longer. Although our results suggest that increased variety may be a tool to keep workers at the firm, the lack of variety may also be a tool. Many operations are built on the idea of substituting low-skilled labor for higher cost machines (e.g., see Huckman and MacCormack 2009). The economics of these models depend on low-cost labor which often means workers with limited experience. In other words, high experience workers who cost more are not desired and may need to be encouraged to leave the firm (assuming that simply letting the worker go is impossible or at least undesirable). By pursuing a specialized strategy a firm may be able to capture the short-term benefits of repetition while ensuring a constant turnover of its workforce. The desired tradeoff would depend on both the learning rate and the salary structure in a given context.

Our work also has important implications for operational performance given the ongoing fragmentation of work. Advances in information and communication technologies are permitting organizations to divide work up into very small pieces and then to distribute these tasks to workers who may or may not be collocated (c.f., Levy and Murnane 2004). In the case of Shinsei, the company redesigned their home loan mortgage process with the objective of removing human variability and instead having the information technology system control the process. While the potential gains from information technology may be worthwhile, this study highlights that task assignment still plays an important role in determining worker productivity - we find that behavioral elements still impact completion time. While ongoing advances in technology may create opportunities, for virtual factories (Stross 2010), our results highlight the need to identify and then implement algorithms for task assignment, in such a context, that consider the gains and costs from both specialization and variety.

Altogether our results highlight that in task assignment the important relationship to examine is not specialization versus variety, but rather specialization and variety. 
Table 1. Description of stages analyzed.

\begin{tabular}{lcl}
\hline Name & $\begin{array}{c}\text { Separate } \\
\text { Stages }\end{array}$ & Description \\
\hline Custodian & 2 & Scans and actual documents are compared to confirm quality (initial and additional data). \\
\hline $\begin{array}{l}\text { Doc tagging } \\
\text { Application } \\
\text { capture }\end{array}$ & 2 & Images on scanned documents are tagged for data entry (initial and additional data). \\
\hline $\begin{array}{l}\text { Preliminary } \\
\text { information }\end{array}$ & 2 & $\begin{array}{l}\text { Data from application forms are entered into the computer (divided into two separate } \\
\text { stages for different forms for initial and additional application capture). }\end{array}$ \\
\hline $\begin{array}{l}\text { Credit check } \\
\text { Income tax }\end{array}$ & 2 & $\begin{array}{l}\text { Specific fields of data from additional forms are entered into the computer (divided into } \\
\text { two separate stages corresponding to different forms). }\end{array}$ \\
\hline Real estate & 2 & Stage 1 requests a credit report, while stage 2 enters the data from the report. \\
\hline Credit approval & 1 & Stage 1 requests tax verification data, while stage 2 enters the data from the report. \\
\hline
\end{tabular}

Table 2. Control variables.

\begin{tabular}{|c|c|}
\hline Name & Description \\
\hline Load & $\begin{array}{l}\text { Prior work finds that workers increase their processing speed as the load on a system increases (Schultz et } \\
\text { al. 1998; KC and Terwiesch 2009). Following KC and Terwiesch (2009), we construct a variable, load, that } \\
\text { measures the percentage of workers who completed transactions in the hour that the focal task started. }\end{array}$ \\
\hline Overwork & 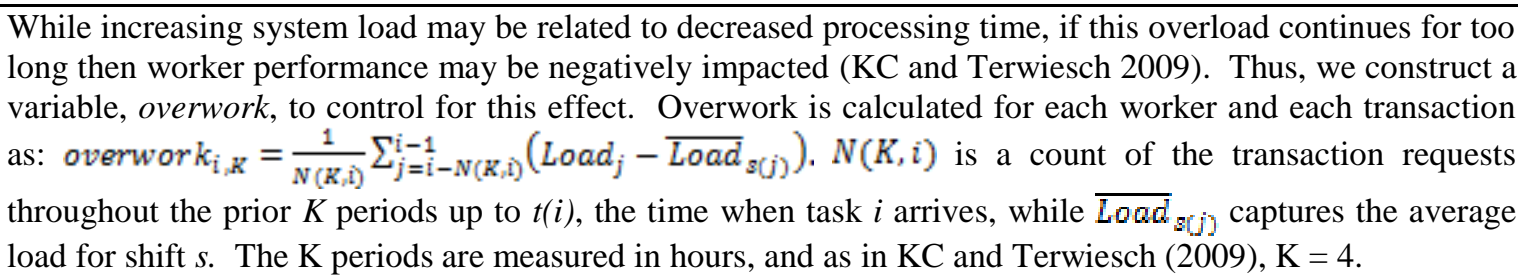 \\
\hline Utilization & $\begin{array}{l}\text { Workers lack queue awareness, but managers can view system backlog. While managers do not reallocate } \\
\text { volume based on backlog, it is possible that managers could encourage workers to work faster. Also, a } \\
\text { higher backlog decreases the likelihood that the system will allocate a different stage to a worker. Thus, we } \\
\text { control for the utilization for the system on a monthly basis. We divide total minutes that workers were } \\
\text { working by total minutes available to work (shift length minus lunch and breaks), for the prior thirty days. } \\
\text { For the first month we calculate utilization for all prior days setting the value to zero for the first day. }\end{array}$ \\
\hline Defect & $\begin{array}{l}\text { At Shinsei two workers complete data entry tasks and outputs are compared. If a discrepancy appears, the } \\
\text { work is given to two other workers. This process repeats until two workers' output agrees. Therefore, we } \\
\text { construct an indicator variable, defect, that equals one if an output was rejected and is zero otherwise. }\end{array}$ \\
\hline $\begin{array}{l}\text { Stage } \\
\text { Change }\end{array}$ & $\begin{array}{l}\text { We construct an indicator variable set to one when a stage change occurs (when a worker switches from } \\
\text { completing work in one stage to doing so in another during the same workday), otherwise this variable is set } \\
\text { to zero. When workers change stages, they do not change physical stations. }\end{array}$ \\
\hline $\begin{array}{l}\text { Day-of- } \\
\text { Week }\end{array}$ & $\begin{array}{l}\text { To control for day-of-week effects (Bryson and Forth 2007; Anbalagan and Vouk 2009; Schultz, } \\
\text { Schoenherr and Nembhard 2010), we construct indicators for Tuesday through Saturday (Monday is the } \\
\text { missing category). Work during the week is from 9:00am to 6:00pm . On Saturday, work begins at 9:00am, } \\
\text { and ends when the work is finished. Realized volume for Monday through Saturday is 21\%, 18\%, 20\%, } \\
19 \%, 18 \% \text {, and 4\%, respectively. }\end{array}$ \\
\hline $\begin{array}{l}\text { Year } \\
\text { Indicators }\end{array}$ & $\begin{array}{l}\text { We add indicators for the year each task was completed (with } 2007 \text { as the excluded category). This variable } \\
\text { controls for any environmental differences across time. }\end{array}$ \\
\hline $\begin{array}{l}\text { Stage } \\
\text { indicators }\end{array}$ & $\begin{array}{l}\text { In order to compare performance across stages, we control for stage differences by including indicators for } \\
\text { all but one of the } 17 \text { stages that appear in the data. }\end{array}$ \\
\hline $\begin{array}{l}\text { Individual } \\
\text { indicators }\end{array}$ & $\begin{array}{l}\text { To control for time-invariant aspects of workers, such as innate skill, we include indicators set to one when } \\
\text { a worker completes a task and zero otherwise. All productivity hypotheses are tested "within-worker." }\end{array}$ \\
\hline
\end{tabular}


Table 3. Summary Statistics for Productivity Analysis $(n=598,393)$.

\begin{tabular}{|c|c|c|c|c|c|c|c|c|c|c|c|}
\hline Variable & Mean & $\sigma$ & 1 & 2 & 3 & 4 & 5 & 6 & 7 & 8 & 9 \\
\hline 1. Log completion time & 0.39 & 1.15 & & & & & & & & & \\
\hline 2. Same day stage-specific volume & 62.0 & 73.7 & -0.20 & & & & & & & & \\
\hline 3. Same day other stage volume & 61.7 & 92.5 & -0.12 & 0.02 & & & & & & & \\
\hline 4. Prior day stage-specific volume & 2,326 & 2,362 & -0.15 & 0.24 & 0.09 & & & & & & \\
\hline 5. Prior day other stage volume & 2,977 & 3,302 & 0.01 & 0.00 & 0.20 & 0.25 & & & & & \\
\hline 6. Load & 0.64 & 0.23 & -0.10 & 0.19 & 0.12 & -0.02 & -0.05 & & & & \\
\hline 7. Overwork & 0.01 & 0.21 & -0.04 & $\mathbf{0 . 0 2}$ & 0.02 & -0.01 & 0.01 & 0.70 & & & \\
\hline 8. Utilization & 0.52 & 0.06 & 0.01 & -0.01 & -0.01 & 0.00 & 0.00 & 0.14 & 0.01 & & \\
\hline 9. Stage change & 0.07 & 0.26 & 0.04 & -0.06 & 0.05 & -0.03 & 0.12 & -0.05 & 0.00 & -0.02 & \\
\hline 10. Defect & 0.03 & 0.16 & 0.06 & 0.06 & -0.01 & 0.00 & -0.08 & 0.02 & -0.01 & 0.00 & -0.02 \\
\hline
\end{tabular}

Note. Bold denotes significance of less than $5 \%$.

Table 4. Summary Statistics for Turnover Analysis $(n=34,171$ for all variables except lag month rank where $n=30,199)$.

\begin{tabular}{lrrrrrrr}
\hline Variable & Mean & \multicolumn{1}{c}{$\boldsymbol{\sigma}$} & $\mathbf{1}$ & $\mathbf{2}$ & $\mathbf{3}$ & $\mathbf{4}$ & $\mathbf{5}$ \\
\hline 1. Turnover & 0.002 & 0.046 & & & & & \\
2. Cumulative volume & 5,409 & 5,234 & 0.00 & & & & \\
3. Total Variety & 0.35 & 0.23 & 0.00 & $\mathbf{0 . 4 8}$ & & & \\
4. Days at work & 251.8 & 199.4 & 0.00 & $\mathbf{0 . 7 1}$ & $\mathbf{0 . 3 5}$ & & \\
5. Utilization & 0.53 & 0.06 & -0.01 & 0.01 & $\mathbf{- 0 . 0 1}$ & $\mathbf{0 . 0 1}$ & \\
6. Lag month rank & 23.4 & 14.4 & 0.00 & $\mathbf{- 0 . 3 2}$ & $\mathbf{- 0 . 2 1}$ & $\mathbf{- 0 . 2 3}$ & $\mathbf{- 0 . 0 5}$ \\
\hline
\end{tabular}

Note. Bold denotes significance of less than 5\%. Seventy-three of the one hundred and eleven workers voluntarily leave the firm during the time of the study 
Table 5. Regression results on completion time of experience $(n=598,393)$.

\begin{tabular}{|c|c|c|c|c|c|}
\hline & \multicolumn{4}{|c|}{ Dependent Variable: Log Completion Time } & \\
\hline & $(1)$ & $(2)$ & (3) & (4) & \\
\hline Same day stage-specific volume & $\begin{array}{c}-3.487 \mathrm{e}-04 * * * \\
(1.616 \mathrm{e}-05)\end{array}$ & $\begin{array}{c}-4.045 \mathrm{e}-04 * * * \\
(1.829 \mathrm{e}-05)\end{array}$ & $\begin{array}{c}-3.787 \mathrm{e}-04 * * * \\
(1.829 \mathrm{e}-05)\end{array}$ & $\begin{array}{c}-3.661 \mathrm{e}-04 * * * \\
(1.964 \mathrm{e}-05)\end{array}$ & \multirow{2}{*}{ Hypothesis 1} \\
\hline Same day other stage volume & $\begin{array}{c}-1.241 \mathrm{e}-04 * * * \\
(1.120 \mathrm{e}-05)\end{array}$ & $\begin{array}{c}-2.101 \mathrm{e}-04 * * * \\
(1.507 \mathrm{e}-05)\end{array}$ & $\begin{array}{c}-2.062 \mathrm{e}-04 * * * \\
(1.504 \mathrm{e}-05)\end{array}$ & $\begin{array}{c}-1.636 \mathrm{e}-04 * * * \\
(1.716 \mathrm{e}-05)\end{array}$ & \\
\hline Same day stage-specific volume $\times$ & & $9.833 \mathrm{e}-07 * * *$ & $9.776 \mathrm{e}-07 * * *$ & $7.937 \mathrm{e}-07 * * *$ & \multirow{2}{*}{ Hypothesis 2} \\
\hline Same day other stage volume & & $(1.006 \mathrm{e}-07)$ & $(1.002 \mathrm{e}-07)$ & $(1.059 \mathrm{e}-07)$ & \\
\hline Prior day stage-specific volume & $\begin{array}{c}-5.188 \mathrm{e}-05^{* * *} \\
(1.746 \mathrm{e}-06)\end{array}$ & $\begin{array}{c}-4.126 \mathrm{e}-05 * * * \\
(1.944 \mathrm{e}-06)\end{array}$ & $\begin{array}{c}-1.453 \mathrm{e}-04 * * * \\
(4.742 \mathrm{e}-06)\end{array}$ & $\begin{array}{c}-2.259 \mathrm{e}-05^{* * * *} \\
(2.203 \mathrm{e}-06)\end{array}$ & \multirow[b]{5}{*}{ Hypothesis 3} \\
\hline Prior day stage-specific volume ${ }^{2}$ & $\begin{array}{c}4.078 \mathrm{e}-09 * * * \\
(1.267 \mathrm{e}-10)\end{array}$ & $\begin{array}{c}4.749 \mathrm{e}-09 * * * \\
(1.357 \mathrm{e}-10)\end{array}$ & $\begin{array}{l}2.297 \mathrm{e}-08 * * * \\
(7.232 \mathrm{e}-10)\end{array}$ & $\begin{array}{c}3.592 \mathrm{e}-09 * * * \\
(1.824 \mathrm{e}-10)\end{array}$ & \\
\hline Prior day other stage volume & $\begin{array}{c}-1.735 \mathrm{e}-05^{* * *} \\
(1.754 \mathrm{e}-06)\end{array}$ & $\begin{array}{c}-9.029 \mathrm{e}-06^{* * * *} \\
(1.772 \mathrm{e}-06)\end{array}$ & $\begin{array}{c}-1.267 \mathrm{e}-05^{* * *} \\
(2.626 \mathrm{e}-06)\end{array}$ & $\begin{array}{c}1.298 \mathrm{e}-05^{* * *} \\
(2.213 \mathrm{e}-06)\end{array}$ & \\
\hline Prior day other stage volume ${ }^{2}$ & $\begin{array}{c}9.867 \mathrm{e}-10 * * * \\
(1.048 \mathrm{e}-10)\end{array}$ & $\begin{array}{c}9.595 \mathrm{e}-10 * * * \\
(1.047 \mathrm{e}-10)\end{array}$ & $\begin{array}{c}6.188 \mathrm{e}-10^{* * *} \\
(1.806 \mathrm{e}-10)\end{array}$ & $\begin{array}{l}3.546 \mathrm{e}-10^{* *} \\
(1.302 \mathrm{e}-10)\end{array}$ & \\
\hline $\begin{array}{l}\text { Prior day stage-specific volume } \times \\
\text { Prior day other stage volume }\end{array}$ & & $\begin{array}{c}-3.297 \mathrm{e}-09^{* * *} \\
(2.356 \mathrm{e}-10)\end{array}$ & $\begin{array}{c}1.404 \mathrm{e}-08 * * * \\
(1.716 \mathrm{e}-09)\end{array}$ & $\begin{array}{c}-4.183 \mathrm{e}-09^{* * *} \\
(3.404 \mathrm{e}-10)\end{array}$ & \\
\hline $\begin{array}{l}\text { Prior day stage-specific volume } e^{2} \times \\
\text { Prior day other stage volume }\end{array}$ & \multicolumn{4}{|c|}{$\begin{array}{c}-3.641 \mathrm{e}-12 * * * \\
(2.347 \mathrm{e}-13)\end{array}$} & \\
\hline Prior day stage-specific volume $\times$ & \multicolumn{4}{|c|}{$-4.303 e-13^{* * *}$} & \\
\hline Prior day other stage volume ${ }^{2}$ & \multicolumn{4}{|c|}{$(1.418 \mathrm{e}-13)$} & \\
\hline Prior day stage-specific volume ${ }^{2} \times$ & \multicolumn{4}{|c|}{$1.384 \mathrm{e}-16^{* * *}$} & \\
\hline Prior day other stage volume ${ }^{2}$ & \multicolumn{4}{|c|}{$(1.987 \mathrm{e}-17)$} & \\
\hline Load & $\begin{array}{c}-0.3913 * * * \\
(0.0100)\end{array}$ & $\begin{array}{c}-0.3744 * * * \\
(0.0100)\end{array}$ & $\begin{array}{c}-0.3622 * * * \\
(0.0100)\end{array}$ & $\begin{array}{c}-0.3065 * * * \\
(0.0125)\end{array}$ & \\
\hline Overwork & $\begin{array}{c}0.2408^{* * *} \\
(0.0097)\end{array}$ & $\begin{array}{c}0.2274 * * * \\
(0.0097)\end{array}$ & $\begin{array}{c}0.2168 * * * \\
(0.0097)\end{array}$ & $\begin{array}{c}0.1669^{* * *} \\
(0.0117)\end{array}$ & \\
\hline Utilization & $\begin{array}{c}-0.1409 * * * \\
(0.0263)\end{array}$ & $\begin{array}{c}-0.1394 * * * \\
(0.0263)\end{array}$ & $\begin{array}{c}-0.1501 * * * \\
(0.0261)\end{array}$ & $\begin{array}{c}-0.08350 * * \\
(0.0266)\end{array}$ & \\
\hline Stage change & $\begin{array}{c}0.0758 * * * \\
(0.0036)\end{array}$ & $\begin{array}{c}0.0755^{* * *} \\
(0.0036)\end{array}$ & $\begin{array}{c}0.0753 * * * \\
(0.0036)\end{array}$ & $\begin{array}{c}0.0900 * * * \\
(0.0044)\end{array}$ & \\
\hline Defect & $\begin{array}{c}0.3034 * * * \\
(0.0067)\end{array}$ & $\begin{array}{c}0.3037 * * * \\
(0.0067)\end{array}$ & $\begin{array}{c}0.3030 * * * \\
(0.0067)\end{array}$ & $\begin{array}{c}0.3285^{* * *} \\
(0.0069)\end{array}$ & \\
\hline Year Indicators & Significant & Significant & Significant & Significant & \\
\hline Day Indicators & Significant & Significant & Significant & Significant & \\
\hline Stage Indicators & Significant & Significant & Significant & Significant & \\
\hline Individual Indicators & Significant & Significant & Significant & Significant & \\
\hline Constant & $\begin{array}{c}-2.1635^{* * *} \\
(0.0688)\end{array}$ & $\begin{array}{c}-2.1620 * * * \\
(0.0688)\end{array}$ & $\begin{array}{c}-2.1462 * * * \\
(0.0685)\end{array}$ & $\begin{array}{c}-2.2081 * * * \\
(0.1047)\end{array}$ & \\
\hline Observations & 598,393 & 598,393 & 598,393 & 462,397 & \\
\hline Number of Individuals & 111 & 111 & 111 & 95 & \\
\hline R-Squared & 0.3384 & 0.3388 & 0.3424 & 0.3291 & \\
\hline Wald Chi-Squared & $357911 * * *$ & $353189 * * *$ & $355321 * * *$ & $255941 * * *$ & \\
\hline
\end{tabular}


Table 6. Additional detail on day of week and year indicators from models in Table $5(n=598,393)$.

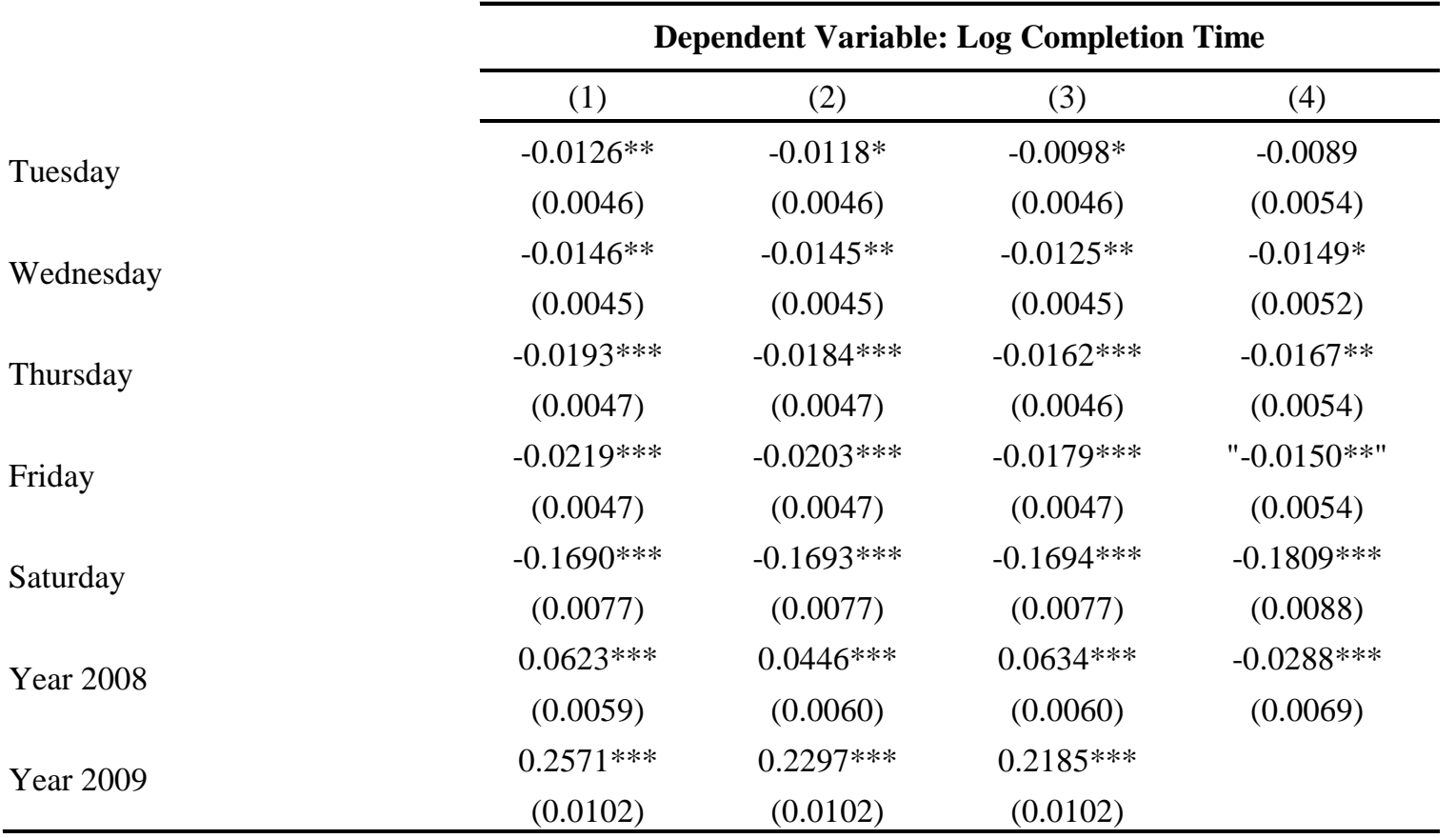

Notes. *, ${ }^{*}$ and ${ }^{* * *}$ denote signficance at the $5 \%, 1 \%$ and $0.1 \%$ levels, respectively.

Table 7. Regression results on worker leaving of experience and control variables.

\begin{tabular}{|c|c|c|c|}
\hline \multirow{4}{*}{ Total Variety } & \multicolumn{2}{|c|}{ Dependent Variable: Worker left the firm } & \multirow{4}{*}{ Hypothesis 4} \\
\hline & (1) & (2) & \\
\hline & $-1.5174^{*}$ & $-1.4559 *$ & \\
\hline & $(0.7073)$ & $(0.7041)$ & \\
\hline \multirow{2}{*}{ Days Working } & $-0.0056 * * *$ & $-0.0065 * * *$ & \\
\hline & $(0.0012)$ & $(0.0013)$ & \\
\hline \multirow{2}{*}{ Utilization } & -2.3811 & -2.7188 & \\
\hline & $(1.9471)$ & $(1.8758)$ & \\
\hline \multirow{2}{*}{ Year Indicator 2008} & -0.2044 & -0.1480 & \\
\hline & $(0.3796)$ & $(0.3671)$ & \\
\hline \multirow{2}{*}{ Year Indicator 2009} & -0.0539 & 0.4202 & \\
\hline & $(0.5515)$ & $(0.5386)$ & \\
\hline \multirow{2}{*}{ Lag Month Rank } & & $0.0295 *$ & \\
\hline & & $(0.0135)$ & \\
\hline Observations & 34,171 & 30,199 & \\
\hline Workers & 111 & 111 & \\
\hline Workers who left & 73 & 73 & \\
\hline R-Squared & 0.0564 & 0.0614 & \\
\hline Log likelihood & -642.9 & -633.6 & \\
\hline Wald Chi-Squared & $68.0000 * * *$ & $65.6818 * * *$ & \\
\hline
\end{tabular}


Figure 1. Process flow diagram for Shinsei loan process (parts of the process in white are included in the analyses).

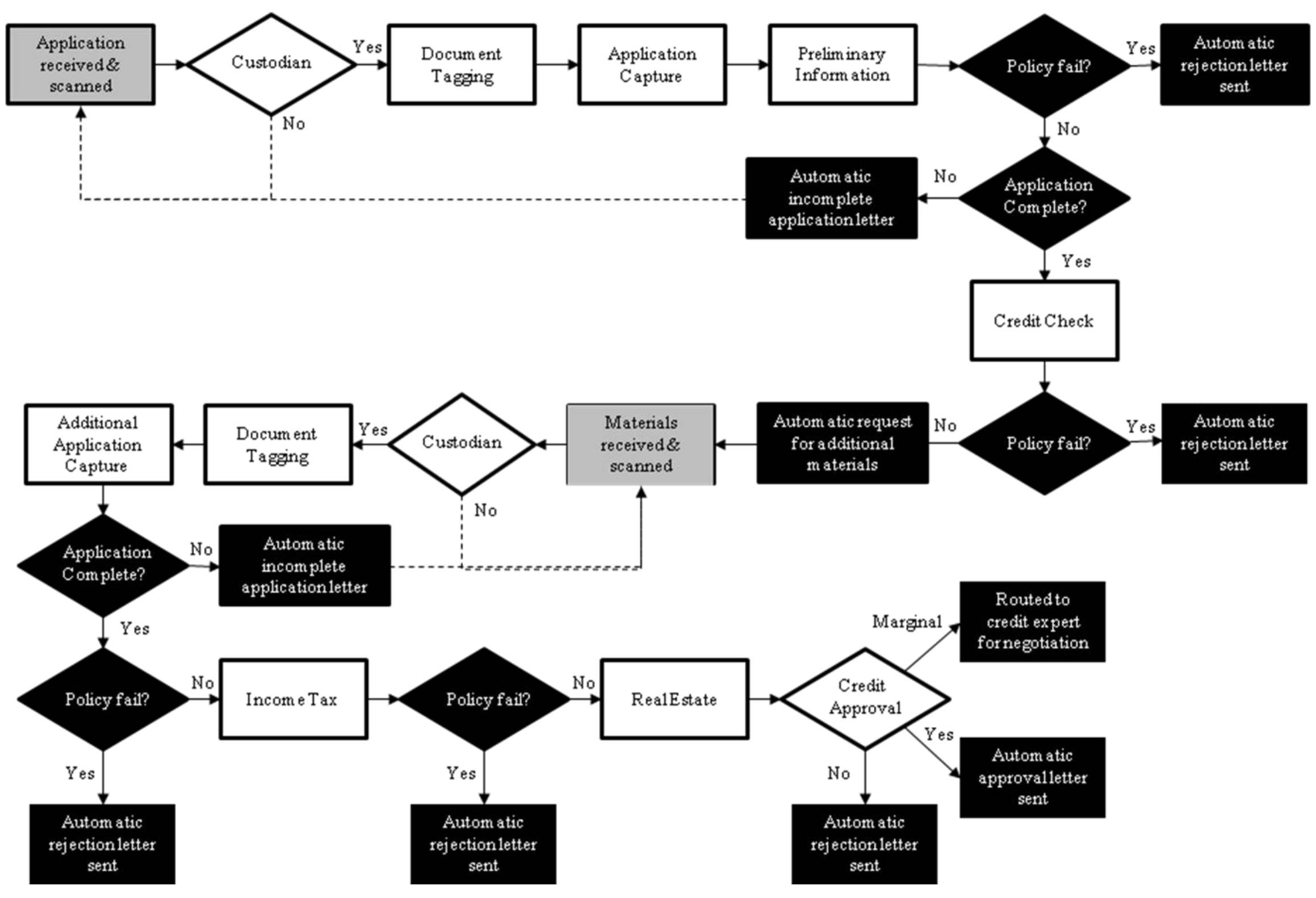


Figure 2. Plot from Table 5, Column 2, examining the net effect of variety on performance.

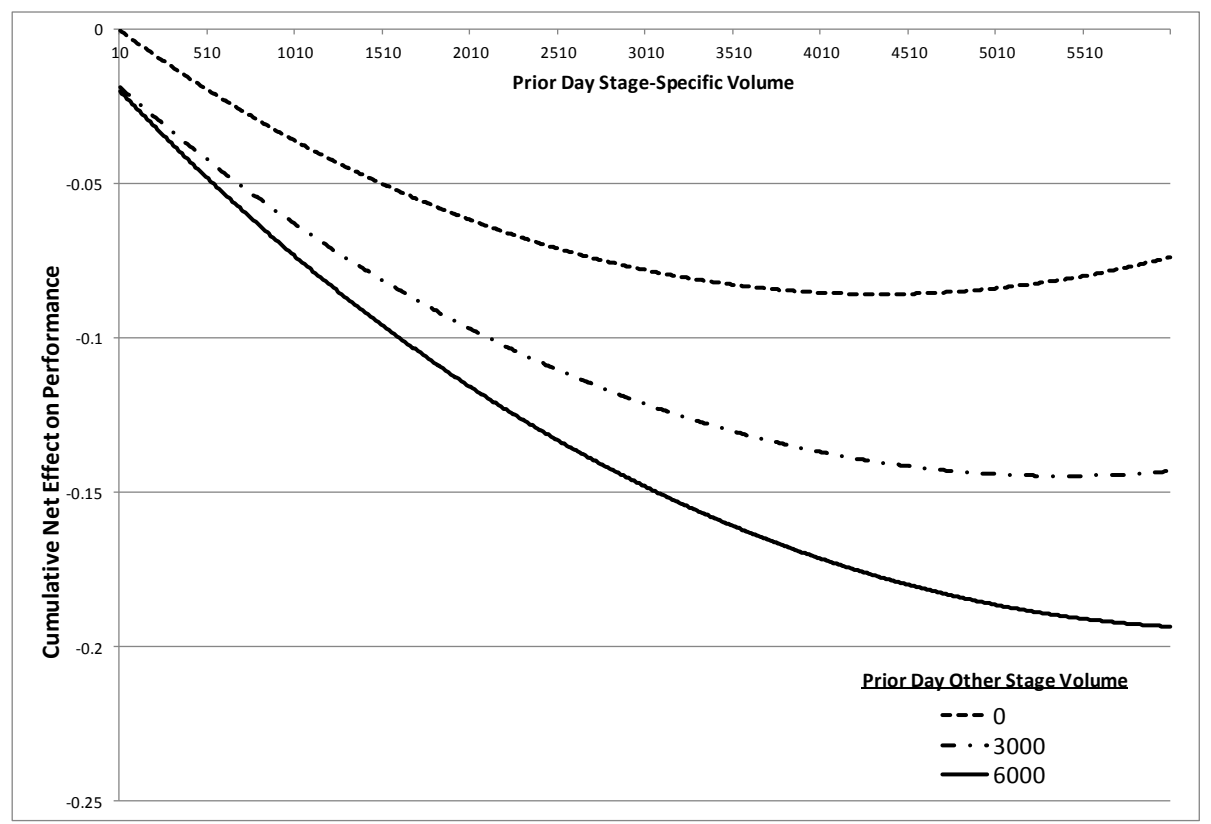

Note: We plot the net effects for the $\mu$ and plus or minus one $\sigma$ for prior day other stage volume (approximately 0, 3000, and 6000), while prior day stage-specific volume varies from 0 to 6000. Thus, we plot the following curves over that range with the estimated coefficients from Table 5, Column 2: $\left(\beta_{4}\right.$ Prior Day Stage-SpecificVolume $+\beta$ Prior Day Stage-SpecificVolume ${ }^{2}+\beta_{6}$ Prior Day OtherStage Volume + e $\quad \beta$ Prior Day Other Stage Volume ${ }^{2}+\beta_{g}$ Prior Day Stage-Specific Volume $x$ Prior Day Other Stage Volume ) - 1

Figure 3. Plot from Table 5, Column 3, examining the net effect of variety on performance.

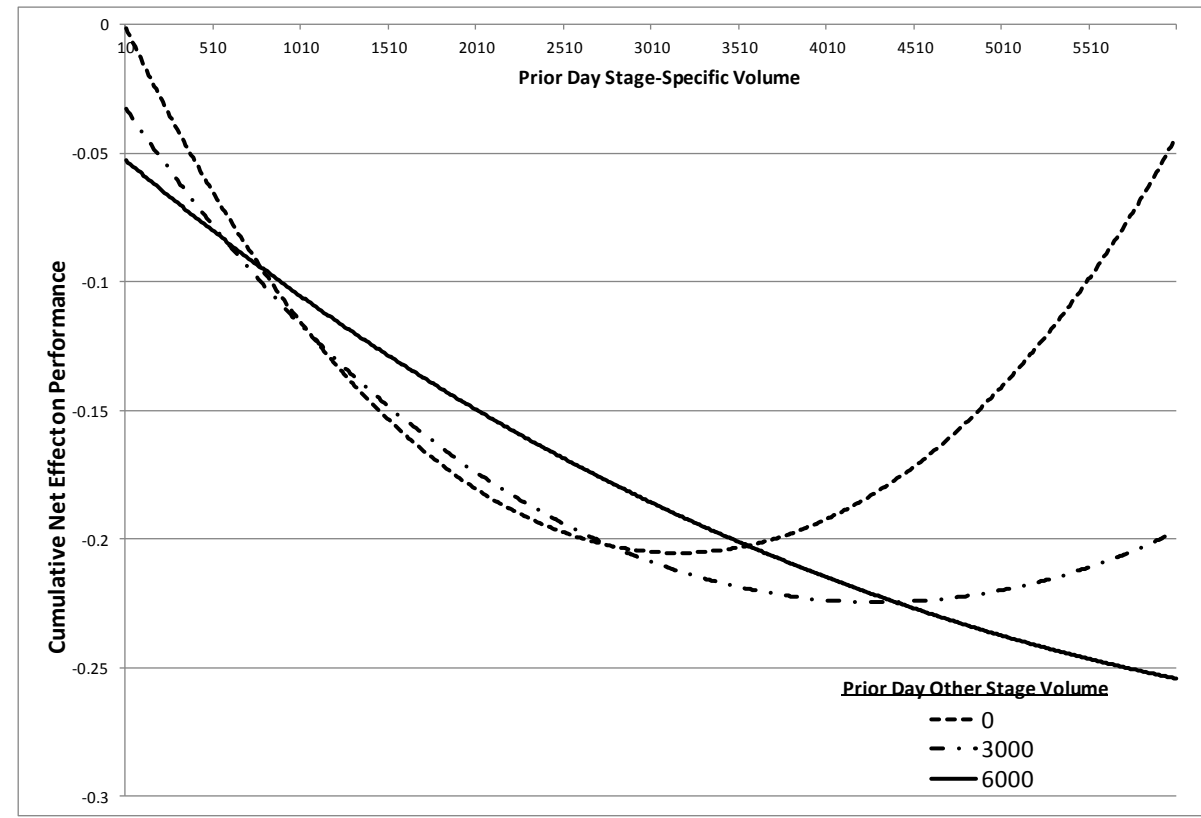

Note: We plot the same figure as in Figure 2, substituting the full quadratic expansion of the interaction effect and the estimates in Table 5, Column 3. 


\section{References}

Allahverdi, A., J. N. D. Gupta, et al. (1999). "A review of scheduling research involving setup considerations." Omega 27(2): 219-239.

Allport, A., E. A. Styles, et al. (1994). Shifting intentional set. Attention and Performance XV. C. Umilta and M. Moscovitch. Cambridge, MA, MIT Press: 421-452.

Anbalagan, P. and M. Vouk (2009). ""Days of the week" effect in predicting the time taken to fix defects." Proceedings of the 2nd International Workshop on Defects in Large Software Systems.

Argote, L. (1999). Organizational Learning: Creating, Retaining, and Transferring Knowledge. Boston, Kluwer Academic.

Argote, L., S. L. Beckman, et al. (1990). "The persistence and transfer of learning in industrial settings." Management Science 36(2): 140-154.

Argote, L. and E. Miron-Spektor (2010). "Organizational learning: From experience to knowledge." Organization Science.

Argyris, C. and D. A. Schön (1978). Organizational learning. Reading, Mass., Addison-Wesley Pub. Co. Baddeley, A. (1992). "Working memory." Science 255(5044): 556-559.

Bahl, H. C., L. P. Ritzman, et al. (1987). "Determining lot sizes and resource requirements: A review." Operations Research 35(3): 329-345.

Bailey, C. D. (1989). "Forgetting and the learning curve: A laboratory study." Management Science 35(3): 340-352.

Beck, N. (2001). "Time-series cross-section data: What have we learned in the past few years?" Annual Review of Political Science 4: 271-293.

Bendoly, E., K. Donohue, et al. (2006). "Behavior in operations management: Assessing recent findings and revisiting old assumptions." Journal of Operations Management 24(6): 737-752.

Boh, W. F., S. A. Slaughter, et al. (2007). "Learning from experience in software development: A multilevel analysis." Management Science 53(8): 1315-1331.

Boudreau, J., W. Hopp, et al. (2003). "On the interface between operations and human resources management." Manufacturing \& Service Operations Management 5(3): 179-202.

Bryson, A. and J. Forth (2007). "Are there day of the week productivity effects?" Center for Economic Performance, Manpower Human Resources Lab: Document number MHRLdp004, London School of Economics.

Cameron, A. C., J. B. Gelbach, et al. (Forthcoming). "Robust inference with multi-way clustering." Journal of Business and Economic Statistics.

Cellier, J.-M. and H. Eyrolle (1992). "Interference between switched tasks." Ergonomics 35(1): 25 - 36.

Clark, J. R. and R. S. Huckman (2010). Broadening focus: Spillovers and the benefits of specialization in the hospital industry. Harvard Business School Working Paper, No. 09-120. Boston.

Cleves, M. A., W. W. Gould, et al. (2004). An Introduction to Survival Analysis Using Stata. College Station, TX, Stata Press.

Darr, E. D., L. Argote, et al. (1995). "The acquisition, transfer, and depreciation of knowledge in service organizations: Productivity in franchises." Management Science 41(11): 1750-1762.

Drucker, P. F. (1999). Management Challenges for the 21st Century. New York, HarperBusiness.

Dutton, J. M. and A. Thomas (1984). "Treating progress functions as a managerial opportunity." Academy of Management Review 9(2): 235-247.

Edmondson, A. C. (2002). "The local and variegated nature of learning in organizations: A group-level perspective." Organization Science 13(2): 128.

Ellis, H. C. (1965). The transfer of learning. New York, Macmillan.

Fisher, C. D. (1993). "Boredom at work: A neglected concept." Human Relations 46(3): 395-417.

Fisher, M. L. and C. D. Ittner (1999). "The impact of product variety on automobile assembly operations: Empirical evidence and simulation analysis." Management Science 45(6): 771-786. 
Fried, Y. and G. R. Ferris (1987). "The validity of the job characteristics model: A review and metaanalysis." Personnel Psychology 40(2): 287-322.

Gino, F., L. Argote, et al. (2010). "First, get your feet wet: The effects of learning from direct and indirect experience on team creativity." Organizational Behavior and Human Decision Processes 111(2): 102-115.

Gino, F. and G. P. Pisano (2008). "Toward a theory of behavioral operations." Manufacturing and Service Operations Management 10(4): 676-691.

Greenhalgh, L. and Z. Rosenblatt (1984). "Job insecurity: Toward conceptual clarity." Academy of Management Review 9(3): 438-448.

Griffeth, R. W., P. W. Hom, et al. (2000). "A meta-analysis of antecedents and correlates of employee turnover." Journal of Management 26(3): 463-488.

Hackman, J. R. (1969). "The nature of the task as a determiner of job behavior." Personnel Psychology 22: $435-444$.

Hackman, J. R. and G. R. Oldham (1976). "Motivation through the design of work: Test of a theory." Organizational Behavior and Human Performance 16(2): 250-279.

Harrison, D. A. and K. J. Klein (2007). "What's the difference? Diversity constructs as separation, variety, or disparity in organizations." Academy of Management Review 32(4): 1199-1228.

Hayes, R. H. and S. C. Wheelwright (1984). Restoring our Competitive Edge: Competing through Manufacturing. New York, Wiley.

Herzberg, F. (1968). "One more time: How do you motivate employees?" Harvard Business Review 46(1): 53-62.

Huckman, R. S. and A. MacCormack (2009). "BYD Company, Ltd." HBS Case \#606-139.

Huckman, R. S. and G. P. Pisano (2006). "The firm specificity of individual performance: Evidence from cardiac surgery." Management Science 52(4): 473-488.

Huckman, R. S. and D. Zinner (2008). "Does focus improve operational performance? Lessons from the management of clinical trials." Strategic Management Journal 29(2): 173-193.

Humphrey, S. E., J. D. Nahrgang, et al. (2007). "Integrating motivational, social, and contextual work design features: A meta-analytic summary and theoretical extension of the work design literature." Journal of Applied Psychology 92(5): 1332-1356.

Ichniowski, C. and K. Shaw (1999). "The effects of human resource management systems on economic performance: An international comparison of U.S. and Japanese plants." Management Science 45(5): 704-721.

Jaikumar, R. and R. E. Bohn (1992). "A dynamic approach to operations management: An alternative to static optimization." International Journal of Production Economics 27(3): 265-282.

KC, D. and C. Terwiesch (2009). "Impact of workload on service time and patient safety: An econometric analysis of hospital operations." Management Science 55(9): 1486-1498.

KC, D. and C. Terwiesch (2010). The effects of focus on performance: Evidence from California hospitals. Working paper.

Langer, E. J. (1989). Mindfulness. Reading, MA, Addison-Wesley.

Lapré, M. A., A. S. Mukherjee, et al. (2000). "Behind the learning curve: Linking learning activities to waste reduction." Management Science 46(5): 597-611.

Lapré, M. A. and N. Tsikriktsis (2006). "Organizational learning curves for customer dissatisfaction: Heterogeneity across airlines." Management Science 52(3): 352-366.

Levy, F. and R. J. Murnane (2004). The New Division of Labor: How Computers are Creating the Next Job Market. Princeton, N.J., Princeton University Press.

Levy, F. K. (1965). "Adaptation in the production process." Management Science 11(6): B136-B154.

Lindbeck, A. and D. J. Snower (2000). "Multitask learning and the reorganization of work: From Tayloristic to holistic organization." Journal of Labor Economics 18(3): 353-376.

Loch, C. H. and Y. Wu (2007). Behavioral Operations Management. Hanover, MA, now Publishers. 
MacDuffie, J. P., K. Sethuraman, et al. (1996). "Product variety and manufacturing performance: Evidence from the international automotive assembly plant study." Management Science 42(3): 350-369.

Mukherjee, A., W. Mitchell, et al. (2000). "The impact of new manufacturing requirements on production line productivity and quality at a focused factory." Journal of Operations Management 18: 139168.

Narayanan, S., S. Balasubramanian, et al. (2009). "A matter of balance: Specialization, task variety, and individual learning in a software maintenance environment." Management Science 55(11): 18611876.

Nembhard, D. A. and N. Osothsilp (2001). "An empirical comparison of forgetting models." IEEE Transactions on Engineering Management 48(3): 283-291.

Newell, A. and P. Rosenbloom (1981). Mechanisms of skill acquisition \& the power law of practice. Cognitive Skills \& Their Acquisition. J. Anderson. Hillsdale, NJ, Erlbaum: 1-55.

Ortega, J. (2001). "Job rotation as a learning mechanism." Management Science 47(10): 1361-1370.

Piaget, J. (1963). The Psychology of Intelligence. New York, Routledge.

Price, J. L. (1999). "Introduction to the special issue on employee turnover." Human Resource Management Review 9(4): 387-395.

Quinn, R. W. (2005). "Flow in knowledge work: High performance experience in the design of national security technology." Administrative Science Quarterly 50(4): 610-641.

Reagans, R., L. Argote, et al. (2005). "Individual experience and experience working together: Predicting learning rates from knowing who knows what and knowing how to work together." Management Science 51(6): 869-881.

Roethlisberger, F. J. and W. J. Dickson (1934). Management and the Worker. Boston, Harvard University.

Roy, D. F. (1959). ""Banana time": Job satisfaction and informal interaction." Human Organization 18(4): 158-168.

Schendel, J. D. and J. D. Hagman (1982). "On sustaining procedural skills over a prolonged retention interval." Journal of Applied Psychology 67(5): 605-610.

Schilling, M. A., P. Vidal, et al. (2003). "Learning by doing something else: Variation, relatedness, and the learning curve." Management Science 49(1): 39-56.

Schmidt, R. A. (1975). "A schema theory of discrete motor skill learning." Psychological Review 82(4): 225-260.

Schultz, K. L., D. C. Juran, et al. (1998). "Modeling and worker motivation in JIT production systems." Management Science 44(12): 1595-1607.

Schultz, K. L., J. O. McClain, et al. (2003). "Overcoming the dark side of worker flexibility." Journal of Operations Management 21(1): 81-92.

Schultz, K. L., T. Schoenherr, et al. (2010). "An example and a proposal concerning the correlation of worker processing times in parallel tasks." Management Science 56(1): 176-191.

Scott, W. E. (1966). "Activation theory and task design." Organizational Behavior and Human Performance 1(1): 3-30.

Shingo, S. (1989). A Study of the Toyota Production System from an Industrial Engineering Viewpoint. Cambridge, Mass., Productivity Press.

Simons, J. V. and G. R. Russell (2002). "A case study of batching in a mass service operation." Journal of Operations Management 20(5): 577-592.

Skinner, W. (1974). "The focused factory." Harvard Business Review 52(3): 113.

Skinner, W. (1985). The taming of lions: How manufacturing leadership evolved. The Uneasy Alliance: Managing the Productivity-Technology Dilemma. K. B. Clark, R. H. Hayes and C. Lorenz. Boston, Harvard Business School Press.

Smith, A. (1776). An Inquiry into the Nature and Causes of the Wealth of Nations, Edwin Cannan, ed. Library of Economics and Liberty. Retrieved March 9, 2011 from the World Wide Web: http://www.econlib.org/library/Smith/smWN1.html. 
Spear, S. and H. K. Bowen (1999). "Decoding the DNA of the Toyota Production System." Harvard Business Review 77(5): 97-106.

Staw, B. M. (1980). "The consequences of turnover." Journal of Occupational Behaviour 1(4): 253-273.

Stross, R. (2010). When the Assembly Line Moves Online. New York Times. New York.

Taylor, F. W. (1911). The Principles of Scientific Management. New York, Harper \& Brothers.

Ton, Z. and R. S. Huckman (2008). "Managing the impact of employee turnover on performance: The role of process conformance." Organization Science 19(1): 56-68.

Tsikriktsis, N. (2007). "The effect of operational performance and focus on profitability: A longitudinal study of the U.S. airline industry." Manufacturing \& Service Operations Management 9(4): 506517.

Tucker, A. L., I. M. Nembhard, et al. (2007). "Implementing new practices: An empirical study of organizational learning in hospital intensive care units." Management Science 53(6): 894-907.

Tzur, M. (1996). "Learning in setups: Analysis, minimal forecast horizons, and algorithms." Management Science 42(12): 1732-1743.

Upton, D. M. and J. D. Margolis (1992). "McDonald's Corp." HBS Case \#693-028.

Vroom, V. H. (1964). Work and Motivation. New York, Wiley.

Warr, P. (2007). Work, Happiness, and Unhappiness. Mahwah, NJ, Erlbaum.

Wiersma, E. (2007). "Conditions that shape the learning curve: Factors that increase the ability and opportunity to learn." Management Science 53(12): 1903-1915.

Wright, T. P. (1936). "Factors affecting the cost of airplanes." Journal of Aeronautical Science 3: 122128.

Yelle, L. E. (1979). "The learning curve: Historical review and comprehensive story." Decision Sciences 10(2): 302-328. 